\title{
Von Willebrand factor antigen compared with other factors in vasculitic syndromes
}

\author{
Erhan Ateș, Ayșin Bakkaloğlu, Ümit Saatçi, Oğuz Söylemezoğlu
}

\begin{abstract}
In order to analyse their role as a specific marker of vascular damage and their value in monitoring disease activity the plasma concentrations of von Willebrand factor antigen (vWFAg) and the ristocetin cofactor (RiCoF) activities were determined in 43 children with vasculitis and 20 controls. These patients were subdivided into three groups according to diagnosis: Henoch-Schönlein purpura $(n=18)$, polyarteritis nodosa $(n=16)$, and systemic lupus erythematosus $(n=9)$. High concentrations of vWFAg and activities of $\mathrm{RiCoF}$ were found in all the patient groups. vWFAg and RiCoF returned to normal as the patients became symptom free and remained above normal in those with continuing symptoms. The amount of vWFAg did not correlate with the acute phase reactants. vWFAg acted as a specific marker of vascular damage and was useful for the monitoring of disease activity both in small vessel vasculitis and systemic necrotising arteritis.

(Arch Dis Child 1994; 70: 40-43)
\end{abstract}

Vasculitic syndromes are inflammatory diseases of blood vessels that usually result in destruction of vessel walls and produce vascular occlusion. ${ }^{1}$ Vasculitis may arise de novo as a primary disorder of blood vessels (for example polyarteritis nodosa) or it may occur as a secondary feature of a diverse group of systemic diseases (for example systemic lupus erythematosus). As most vasculitic syndromes have varied modes of presentation and overlapping clinical and pathological features, a laboratory test that supports the diagnosis based on clinical symptoms would be of great interest especially in cases without histological signs of blood vessel involvement.

The von Willebrand factor is a plasma glycoprotein synthesised by megakaryocytes ${ }^{2}$ and endothelial cells ${ }^{3}$ isolated from large and small veins, capillaries, aorta, and arteries that mediates adhesion of platelets to the subendothelium and platelet aggregation by binding to the injured vessel wall. ${ }^{4}$ In recent years various authors have reported an increase of von Willebrand factor antigen (vWFAg) in the plasma in different vasculitic syndromes including scleroderma and Raynaud's phenomenon, ${ }^{5}$ Kawasaki disease, ${ }^{6}$ haemolytic uraemic syndrome, ${ }^{7}$ giant cell arteritis, ${ }^{8}$ and vasculitis in general. ${ }^{9-11}$ Despite this accumulated data on increased vWFAg concentrations, regarded as a reliable index of vascular damage, the correlation of circulating vWFAg concentrations with the changes in clinical findings have been reported only in case reports. ${ }^{10}$ The correlation of vWFAg concentrations with the size of the involved blood vessel is also disputed. ${ }^{911}$ In this study we determined the plasma vWFAg concentrations and the ristocetin induced platelet agglutination (ristocetin cofactor $\mathrm{RiCoF}$ ), which reflects the function of the von Willebrand factor, ${ }^{12}$ in children with vasculitis. We compared the concentrations of vWFAg with the results of the commonly used acute phase reactants. We repeated the tests in remission and in those cases with ongoing clinical symptoms in order to correlate the results with the clinical findings.

\section{Patients and methods}

PATIENTS

The patient population consisted of 43 children and young adults aged 3 to 18 years who were followed up in the paediatric nephrology/rheumatology clinics. There were 18 males and 25 females $(M: F=0 \cdot 7: 1)$. All the patients were studied prospectively; blood was obtained from the patients at the time a diagnosis of vasculitis was made and during the follow up period. The control population consisted of 20 healthy children aged 5 to 15 years with a $\mathrm{M}: \mathrm{F}$ ratio of 1 . Written consent was obtained from the parents.

Patients were subdivided into three groups depending on the diagnosis. There were 18 patients with Henoch-Schönlein purpura who had palpable purpura not related to thrombocytopenia, bowel angina, and in 12 cases histological changes related to leucocytoclastic vasculitis on skin biopsy. Eight patients had concomitant gastrointestinal bleeding and one patient had haematuria. All of the patients fulfilled the criteria of the American College of Rheumatology for the classification of Henoch-Schönlein purpura. ${ }^{13}$ Sixteen patients had polyarteritis nodosa; the diagnosis was obtained on clinical and histological grounds. Patients fulfilled the criteria of the American College of Rheumatology for the classification of polyarteritis nodosa. ${ }^{14}$ Nine patients had systemic lupus erythematosus. The revised American Rheumatism Association criteria were used for the diagnosis. ${ }^{15}$

\section{METHODS}

Clinical assessment

Patients were examined at a time when the disease was considered most active based on clinical features. Palpable purpura, bowel pain, gastrointestinal bleeding, or 
haematuria were observed in patients with Henoch-Schönlein purpura when the disease was active. The observed clinical findings were fever, livedo reticularis, myalgia, arthralgia, testicular pain, or bowel angina in the group with polyarteritis nodosa and malar erythema, photosensitivity, convulsions, or arthritis in those with systemic lupus erythematosus. In 12 patients with Henoch-Schönlein purpura and in all patients with polyarteritis nodosa the diagnosis was confirmed with the histological findings on biopsy. In active disease leucocyte count, the erythrocyte sedimentation rate, and $C$ reactive protein concentrations were raised in those with polyarteritis nodosa and antinuclear antibody, anti-DNA, and complement concentration were outside normal limits in the systemic lupus erythematosus group. In the follow up period the disease was considered inactive when the patient was symptom free and the serological variables were within normal limits. In eight patients clinical findings did not subside during the follow up period of eight months and in these patients repeat test results were obtained in order to monitor the disease activity.

\section{vWFAg assay}

Circulating vWFAg was assayed by an enzyme linked immunosorbent assay (ELISA) using commercially available antisera. ${ }^{16}$ The test was performed in microtitre plates. The first layer was rabbit antihuman vWFAg (Dako) followed by sample or standard, and the third layer was rabbit antihuman vWFAg conjugated with horseradish peroxidase (Dako) which was then developed with $O$-phenylenediamine and hydrogen peroxide and read at $430 \mathrm{~nm}$.

\section{RiCoF assay}

Plasma RiCoF activity was measured by using the macroscopic platelet aggregation test. ${ }^{17}$ Citrated plasma was diluted with isotonic saline from a ratio of $1: 1$ to $1: 160$. Aliquots of $50 \mu \mathrm{l}$ of diluate was made to react with $50 \mu \mathrm{l}$ of a commercially available reagent (Behringwerke) containing stabilised human platelets, ristocetin, and stabilisers on a glass test plate. The last dilution step in which a marked agglutination was observed in comparison with the saline solution control constituted the titre indicating the RiCoF content in per cent when multiplied by the given sensitivity limit. Erythrocyte sedimentation

Table 1 Mean (SD) vWFAg concentrations (\% normal) in patient groups with active disease and in remission

\begin{tabular}{|c|c|c|c|c|c|c|}
\hline Patient group & No & $\begin{array}{l}\text { Active } \\
\text { disease }\end{array}$ & $p$ Value $^{\star}$ & No & Remission & $p$ Value \\
\hline $\begin{array}{l}\text { All patients } \\
\text { Henoch-Schönlein }\end{array}$ & 43 & $251(155)$ & $<0.01$ & 23 & $93(31)$ & $<0.01$ \\
\hline $\begin{array}{l}\text { purpura } \\
\text { Polyarteritis nodosa } \\
\text { Systemic lupus }\end{array}$ & $\begin{array}{l}18 \\
16\end{array}$ & $\begin{array}{l}300(192) \\
237(106)\end{array}$ & $\begin{array}{l}<0.01 \\
<0.01\end{array}$ & $\begin{array}{r}12 \\
9\end{array}$ & $\begin{array}{l}89(26) \\
90(34)\end{array}$ & $\begin{array}{l}<0.01 \\
<0.01\end{array}$ \\
\hline erythematosus & 9 & $243(157)$ & $<0.01$ & 2 & - & - \\
\hline
\end{tabular}

* Statistical evaluation of the patient group compared with the control group.

†Statistical evaluation of the patient group in active disease compared with the same patients in remission.

Mean (SD) control concentrations 72 (21); $\mathrm{n}=20$.

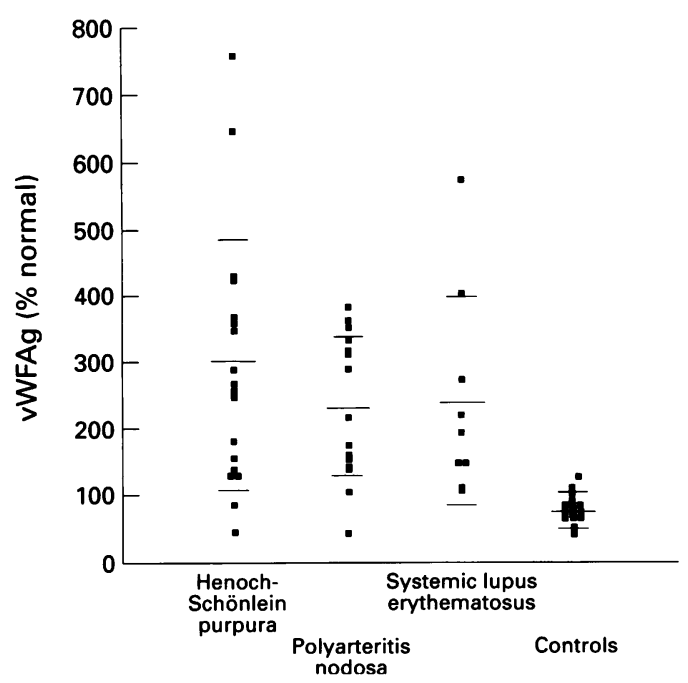

Plasma concentrations of $v W F A g$ in the three patient groups and controls. Horizontal bars indicate mean (SD).

rate, $\mathrm{C}$ reactive protein, fibrinogen, and immune complex assays were performed by standard methods in the clinical laboratories.

\section{Statistical analysis}

The Mann-Whitney U test was used to search for significant differences comparing healthy children with the patient groups. The control test results were compared with the previous results using the Wilcoxon paired test in patients in whom clinical findings subsided. In eight patients with clinical findings during the follow up period the results were evaluated with Fisher's exact $\chi^{2}$ test.

\section{Results}

Circulating vWFAg concentrations were raised in 39 of 43 patients with vasculitis with a mean (SD) of 251 (155) \% normal compared with the control group with 72 (21) \% normal $(p<0.01$; figure). High concentrations compared with the control group were also found in all three subgroups (see table 1). vWFAg concentrations were normal in two patients with Henoch-Schönlein purpura restricted to the skin who had less severe clinical symptoms. In the group with polyarteritis nodosa two patients with myalgia and arthralgia as the dominating symptoms had normal results.

In 23 patients tests were repeated when the patients had no symptoms and the vWFAg concentrations were found to be significantly decreased compared with the previous concentrations $(p<0.01$; table 1$)$. Although high RiCoF activities were found on admission, and returned to normal as the patients became symptom free (table 2), there was no correlation with the vWFAg concentrations in any of the groups.

In all the patients with ongoing clinical findings related to vasculitis vWFAg concentrations remained above normal. When we compared the vWFAg concentrations in each patient's plasma with the values of other laboratory tests performed simultaneously on the patients, there was no significant 
correlation with the erythrocyte sedimentation rate or the concentrations of fibrinogen or immune complexes in the three groups of patients with vasculitis (table 3 ). The concentration of $\mathrm{C}$ reactive protein was related to the vWFAg concentrations in the group with polyarteritis nodosa only $(r=0 \cdot 60)$.

vWFAg and RiCoF were well correlated with the disease activity, with higher than normal results obtained when the patients had disease symptoms and normal values when the symptoms had subsided $(\mathrm{p}<0.001)$. No such correlation was found with the erythrocyte sedimentation rate or the $\mathrm{C}$ reactive protein or fibrinogen concentrations.

\section{Discussion}

vWFAg is synthesised by and present in endothelial cells and it is released from the Weibel-Palade storage bodies induced by different stimuli. ${ }^{18}$ High plasma concentrations have been reported in a variety of diseases affecting blood vessels. In our study we have found that vWFAg and $\mathrm{RiCoF}$ values are raised in the plasma of children with vasculitis and the values were equally high in all three disease subgroups. As these three groups represent small vessel vasculitis, systemic necrotising arteritis and secondary vascular involvement in systemic disease, we consider that high plasma concentrations of vWFAg and $\mathrm{RiCoF}$ activities reflect vascular damage of any size.

In a study of adult patients with vasculitis Woolf $e t$ al assayed factor VIII related antigen (former nomenclature) concentrations and found them to be markedly increased in 34 patients with active systemic necrotising arteritis and large vessel vasculitis, in contrast with 15 patients with active small vessel vasculitis, even when complicated by renal impairment. ${ }^{11}$ They proposed that a distinction could be made between small vessel vasculitis and systemic necrotising arteritis by measuring

Table 2 Mean (SD) RiCoF activities (\% normal) in patient groups with active disease and in remission

\begin{tabular}{lrlllll}
\hline Patient group & No & $\begin{array}{l}\text { Active } \\
\text { disease }\end{array}$ & p Value & No & Remission & p Valuet \\
\hline $\begin{array}{l}\text { All patients } \\
\begin{array}{l}\text { Henoch-Schönlein } \\
\text { purpura }\end{array}\end{array}$ & 43 & $298(154)$ & $<0.01$ & 23 & $110(18)$ & $<0.01$ \\
$\begin{array}{l}\text { Polyarteritis nodosa } \\
\text { Systemic lupus }\end{array}$ & 18 & $367(179)$ & $<0.01$ & 12 & $107(16)$ & $<0.01$ \\
$\quad$ erythematosus & 9 & $266(90)$ & $<0.01$ & 9 & $136(49)$ & $<0.05$ \\
\hline
\end{tabular}

*Statistical evaluation of the patient group compared with the control group.

+ Statistical evaluation of the patient group in active disease compared with the same patients in remission.

Mean (SD) control activities 103 (20); $n=20$.
vWFAg concentrations and thus identify those cases who require invasive investigations. Bowyer et al, comparing two children with systemic polyarteritis nodosa with two children with cutaneous polyarteritis nodosa, found raised vWFAg concentrations only in the group with systemic disease and proposed that these results confirmed the former study despite the limited number of cases. ${ }^{10}$ Thus far a relevant study has not been published to confirm this. We found no difference between our patients with Henoch-Schönlein purpura and polyarteritis nodosa where the vWFAg and $\mathrm{RiCoF}$ values were concerned. We think that a discrimination between small vessel vasculitis and systemic necrotising arteritis cannot be made by vWFAg and these cases require more invasive investigations.

When we repeated the tests in the follow up period we found that vWFAg and $\mathrm{RiCoF}$ decreased to normal in 21 patients among the 23 in remission (tables 1 and 2). In eight patients with ongoing clinical findings followed up for a period of eight months, vWFAg and $\mathrm{RiCoF}$ values remained above normal in all the patients. These were two patients with Henoch-Schönlein purpura admitted with a second attack with findings restricted to the skin, four patients with polyarteritis nodosa with ongoing skin lesions, myalgia and arthralgia, and two patients with systemic lupus erythematosus followed up for arthritis, skin lesions, and convulsions.

When we attempted to correlate acute phase reactants, erythrocyte sedimentation rate, $\mathrm{C}$ reactive protein, and fibrinogen with the vWFAg concentrations, we found no association between the vWFAg and erythrocyte sedimentation rate or fibrinogen. $\mathrm{C}$ reactive protein and vWFAg rose parallel to high concentrations only in the group with polyarteritis nodosa. These results prove that vWFAg does not act as an acute phase reactant but as a specific marker of vascular damage.

We also found that vWFAg and $\mathrm{RiCoF}$ values were well correlated to disease activity with higher than normal results obtained when the patients had disease symptoms and normal values when they became symptom free $(p<0.001)$. No such correlation was found with erythrocyte sedimentation rate, $\mathrm{C}$ reactive protein, or fibrinogen.

In conclusion we have shown that plasma vWFAg concentrations and $\mathrm{RiCoF}$ activities are raised in children with small vessel, systemic necrotising, or secondary vasculitis. These raised values most likely reflect increased amounts of von Willebrand factor released to the circulation from the endothelium because

Table 3 Correlation of selected laboratory variables with vWFAg concentrations in patients with Henoch-Schönlein purpura, polyarteritis nodosa, and systemic lupus erythematosus

\begin{tabular}{|c|c|c|c|c|c|c|c|c|c|c|c|c|}
\hline \multirow[b]{2}{*}{ Laboratory variable } & \multicolumn{4}{|c|}{ Henoch-Schönlein purpura } & \multicolumn{4}{|c|}{ Polyarteritis nodosa } & \multicolumn{4}{|c|}{ Systemic lupus erythematosus } \\
\hline & Mean & No & $\mathbf{r}$ & $p$ Value & Mean & No & $\mathrm{r}$ & p Value & Mean & No & $\mathrm{r}$ & $p$ Value \\
\hline $\begin{array}{l}\text { Erythrocyte sedimentation rate (mm/hour) } \\
\text { C reactive protein }(\mathrm{mg} / \mathrm{l}) \\
\text { Fibrinogen }(\mathrm{g} / \mathrm{l}) \\
\text { Immune complexes }(\mu \mathrm{g} / \mathrm{ml})\end{array}$ & $\begin{array}{c}33 \\
19 \\
3 \cdot 8 \\
167\end{array}$ & $\begin{array}{l}18 \\
16 \\
18 \\
14\end{array}$ & $\begin{array}{l}0 \cdot 28 \\
0 \cdot 20 \\
0 \cdot 01 \\
0 \cdot 19\end{array}$ & $\begin{array}{l}\text { NS } \\
\text { NS } \\
\text { NS }\end{array}$ & $\begin{array}{c}68 \\
78 \\
5 \cdot 8 \\
317\end{array}$ & $\begin{array}{l}16 \\
15 \\
16 \\
12\end{array}$ & $\begin{array}{l}0 \cdot 09 \\
0 \cdot 60 \\
0 \cdot 17 \\
0 \cdot 05\end{array}$ & $\begin{array}{l}\text { NS } \\
<0 \cdot 01 \\
\text { NS } \\
\text { NS }\end{array}$ & $\begin{array}{l}33 \\
8 \\
2 \cdot 8 \\
190\end{array}$ & $\begin{array}{l}9 \\
8 \\
8 \\
4\end{array}$ & $\begin{array}{l}0 \cdot 18 \\
0 \cdot 44 \\
0 \cdot 14 \\
0 \cdot 16\end{array}$ & $\begin{array}{l}\text { NS } \\
\text { NS } \\
\text { NS }\end{array}$ \\
\hline
\end{tabular}

NS $=$ not significant. 
of ongoing vascular damage. We have also found that values returned to normal when the patients were in remission and stayed above normal with sustained clinical findings. The assessment of vWFAg and $\mathrm{RiCoF}$ in vasculitic syndromes can be regarded as reliable tests in monitoring the disease activity.

We thank Professor Arthur Bloom, Cardiff for his advice on the design of this study.

1 Lie JT. Classification and immunodiagnosis of vasculitis; a new solution or promises unfulfilled? $\mathcal{f}$ Rheumatol 1988 ; 15: $728-31$.

2 Sporn LA, Chavin SI, Marder VJ, Wagner DD. Biosynthesis of von Willebrand protein by human Biosynthesis of von Willebrand protein by

3 Jaffe EA, Hoyer LW, Nachman RL. Synthesis of von Jaffe EA, Hoyer LW, Nachman RL. Synthesis of von
Willebrand factor by cultured human endothelial cells. Proc Natl Acad Sci USA 1974; 71: 1906-9.

4 Fretto LJ, Fowler WE, McCaslin DR, Erickson HP, McKee PA. Substructure of human von Willebrand factor. $\mathcal{f}$ Biol Chem 1986; 261: 15679-89.

5 Kahaleh MB, Osborn I, LeRoy EC. Increased factor VIII, von Willebrand factor antigen and von Willebrand factor von Wily in scleroderma and in Raynaud's phenomenon. Ann Intern Med 1981; 94: 482-4.

6 Irazuzta JE, Elbl F, Rees AR. Factor VIII related antigen (von Willebrand's factor) in Kawasaki disease. Clin Pediatr (von Willebrand's factor)

7 Rose PE, Enayat SM, Sunderland R, Short PE, Williams CE, Hill FGH. Abnormalities of factor VIII related protein multimers in the haemolytic uraemic syndrome. Arch Dis Child 1984; 59: 1135-40.

8 Federici AB, Fox RI, Espinoza LR, Zimmerman TS. Elevation of von Willebrand factor is independent of erythrocyte sedimentation rate and persists after gluco- corticoid treatment in giant cell arteritis. Arthritis Rheum 1984; 27: 1046-9.

9 Nusinow SR, Federici AB, Zimmerman TS, Curd JG. Increased von Willebrand factor antigen in the plasma of patients with vasculitis. Arthritis Rheum 1984; 27: 1405-10

10 Bowyer SL, Ragsdale CG, Sullivan DB. Factor VIII related antigen and childhood rheumatic diseases. I Rheumatol antigen and childh

11 Woolf AD, Wakerley G, Wallington TB, Scott DGI, Dieppe PA. Factor VIII related antigen in the assessment of vasculitis. Ann Rheum Dis 1987; 46: 441-7.

12 Marder VJ, Mannucci PM, Firkin BG, Hoyer LW, Meyer D. Standard nomenclature for factor VIII and von Willebrand factor; a recommendation by the international committee on thrombosis and haemostasis. Thromb Haemost 1985; 54: 871-2.

13 Mills JA, Michel BA, Bloch DA, et al. The American College of Rheumatology 1990 Criteria for the classification of Henoch-Schönlein purpura. Arthritis Rheum 1990; 33: 1114-21.

14 Lightfoot RW, Michel BA, Bloch DA, Hunder GG, Zvaifler NJ, McShane DJ. The American College of Rheumatology 1990 criteria for the classification of polyarteritis nodosa. Arthritis Rheum 1990; 33: 1088-93.

15 Tan EM, Cohen AS, Fries JF. The 1982 revised criteria for the classification of systemic lupus erythematosus. Arthritis Rheum 1982; 25: 1271-3.

16 Cejka J. Enzyme immunoassay for factor VIII-related antigen. Clin Chem 1982; 28: 1356-8.

17 Olson JD, Brockway WJ, Fass DN, Magnuson MA, Bowie EJW. Evaluation of ristocetin-Willebrand factor assay and EJW. Evaluation of ristocetin-Willebrand factor assay and 1975; 63: 210-8.

18 Ewenstein BM, Warhol MJ, Handin RI, Pober JS. Composition of the von Willebrand factor storage organelle (Weibel-Palade body) isolated from cultured human umbilical vein endothelial cells. F Cell Biol 1987; 104: 1423-33. 